\title{
The role of small journals and their editors in academic communities or: a message to young researchers on why publishing in small journals is important
}

\author{
Ana Marušić \\ Co-editor in chief, Croatian Medical \\ Journal \\ Member, International Committee of \\ Medical Journal Editors \\ Past President, Council of Science Editors \\ Past President, World Association of \\ Medical Editors
}
Corresponding author: Department of Research in Biomedicine and Health University of Split School of Medicine Šoltanska 2 21000 Split Croatia ana.marusic@mef.hr Tel.: + 38521557812 Fax: + 38521557811

Received: May 3, 2011 Accepted: May 3, 2011

Copyright (C 2011 by Academy of Sciences and Arts of Bosnia and Herzegovina. E-mail for permission to publish: amabih@anubih.ba
When a medical professional becomes a journal editor, he or she is usually not aware of how special and specific their position will be. Being an expert in a certain field and having an academic reputation is usually considered a qualification for an editorial position. Editors are thus often surprised when they learn how complex, technologically advanced and regulated the scientific publishing enterprise in medicine is today $(1,2)$. For editors of small journals in small scholarly communities, following the developments in medical publishing is probably more important than for those in large, prestigious journals (3). This is because small journals from the so-called scientific periphery not only play a role in communicating new knowledge, but also provide education and service to the local community (4-7). In my life as an editor, I have learned the power of small journals to strengthen the local academic community and promote its visibility in the global academic environment.

Small journals thus provide a door for the local community to mainstream science and open a window to global science to see good local research with global relevance $(8,9)$. Journals and their editors do this by introducing and following scientific principles and quality criteria in publishing, which is the best way to educate researchers at local institutions $(1,2)$.

With a background of almost twenty years as editor of a small medical journal, I can give some advice to young academics who are readers of Acta Medica Academica or who are thinking of publishing their first research article - Acta Medica Academica is a good place to test your writing skills and publish reports of your research. Work- 
ing with a journal that embraces the highest international standards in scientific publishing is an important learning experience and preparation for publishing in so-called 'mainstream' scientific journals with greater influence and impact.

Working with journal editors, you will learn about publishing guidelines such as the Uniform Requirements for Manuscripts Submitted to Biomedical Journals of the International Committee of Medical Journal Editors (ICMJE) $(10,11)$. Editors are responsible for the integrity of the published research recorded in their journals and have the obligation to monitor and ensure that the publication process is fair, timely and thorough. They will provide you with their professional and research expertise, gained from the collective knowledge of larger international editorial organizations, such as the ICMJE, the World Association of Medical Editors (WAME), the Council of Science Editors (CSE), as well as the European Association of Science Editors (EASE). They will also be able to provide guidance for all types of publication disputes or ethical problems, because the editorial community is very aware of the detrimental effect such problems may finally have on health care. COPE's ethical flow charts from the Committee on Publication Ethics (COPE) are particularly useful as algorithms for editors to follow when they have an ethical problem in their journal (12). They are available on the COPE web-site (http://publicationethics.org/flowcharts) and are perhaps even more useful for the authors and their institutions because they can learn about processes in research publishing and the rights and responsibilities of all stakeholders in research, from authors and their institutions to journal editors $(1,2)$.

They will also learn about the importance of declaring possible conflicts of interest related to the published work or their general research work (13-15). Declaration of conflicts of interest in special forms is routine practice in most international journals, and using a common declaration form both in small and large journals familiarizes researchers with the complexity of conflicts and related terminology. Having experienced misunderstandings about conflicts of interest, the ICMJE has recently developed a special glossary, which has been translated into several languages, so that local research communities and their members can use the forms adequately to provide a transparent account of their work (16).

Finally, you will learn the latest developments in the transparency of clinical research, which are at the heart of clinical research in all scientific and geographical communities. This means that when you send a report on a clinical trial, you have to have already registered the essential information about the trial in a public register. The ICMJE requirement for trial registration (17-19) has been accepted by the World Health Organization, which has developed a special portal for trial registries - the International Clinical Trials Registry Platform (http://www.who.int/ictrp/en/). The latest revision of the World Medical Association Helsinki Declaration on Ethical Principles for Medical Research Involving Human Subjects from 2008 (http://www.wma.net/ en/30publications/10policies/b3/index. html), also introduced the requirement for trial registration: "Every clinical trial must be registered in a publicly accessible database before recruitment of the first subject." (20). With the most recent opening of the EudraCT database, European journals and their editors, including those in Bosnia and Herzegovina, can make a significant contribution to the process of increasing the transparency of clinical research for the benefit of the public.

When you publish good articles in a small journal it is not only an exceptional opportunity to learn about the medical pub- 
lishing process that is so closely related to academic promotion and research recognition, but you will also contribute to the visibility of the journal itself, so that you will both have great benefits and promote local research (21).

Conflict of interest: The authors declare that they have no conflict of interest. This study was not sponsored by any external organisation.

\section{References}

1. Marušić A, Katavić V, Marušić M. Role of editors and journals in detecting and preventing scientific misconduct: strengths, weaknesses, opportunities, and threats. Med Law. 2007;26:545-66.

2. Marušić A. Approaches to the detection of research misconduct - The role of the peer review process. In: Wells F, Farthing M, eds. Fraud and Misconduct in Biomedical Research. London: The Royal Society of Medicine Press; 2008.

3. Nylena M, Hagve T-A, Marušić A. Small journals and non-English journals. In Godlee F, Jefferson T (ed). Peer review in health sciences. London: BMJ Books; 2003. p. 140-50.

4. Marušić A, Marušić M. Small scientific journals from small countries: breaking from a vicious circle of inadequacy. Croat Med J. 1999;40:508-14.

5. Marušić $M$, Mišak A, Kljaković-Gašpić $M$, Fišter K, Hren D, Marušić A. Producing a scientific journal in a small scientific community: an authorhelpful policy. Int Microbiol. 2004;7:143-7.

6. Sambunjak D, Huić $M$, Hren D, Katić M, Marušić A, Marušić M. What do medical professionals know and think about national and international journals: a cross-sectional study. Learned Publishers. 2009;22:57-70.

7. Marušić M, Marušić A. Good editorial practice: editors as educators. Croat Med J. 2001;42:113-20.

8. Marušić M, Markulin H, Lukić IK, Marušić A. Academic advancement of authors receiving tutoring from a medical journal. Teach Learn Med. 2006;18:126-9.

9. Marušić $A$, Marušić $M$. Teaching students how to read and write science: a mandatory course on scientific research and communication in medicine. Acad Med. 2003;78:1235-9.

10. Laine C, Horton R, DeAngelis CD, Drazen JM, Frizelle FA, Godlee F et al. Clinical trial registra- tion: looking back and moving ahead. Croat Med J. 2007;48:289-91.

11. Drazen JM, Van Der Weyden MB, Sahni P, Rosenberg J, Marušić A, Laine C, et al. Uniform format for disclosure of competing interests in ICMJE journals. Croat Med J. 2009;50:427-8.

12. Wager E, Barbour V, Yentis S, Kleinert S, on behalf of COPE Council. Retractions: Guidance from the Committee on Publication Ethics (COPE). Croat Med J. 2009;50:532-5.

13. Drazen JM, Van Der Weyden MB, Sahni P, Rosenberg J, Marušić A, Laine C, et al. Uniform format for disclosure of competing interests in ICMJE journals. Croat Med J. 2009;50:427-8.

14. Drazen JM, De Leeuw PW, Laine C, Mulrow C, DeAngelis CD, Frizelle FA, et al. Toward more uniform conflict disclosures: the updated ICMJE conflict of interest reporting form. Croat Med J. 2010;51:287-8.

15. Marcovitch H, Barbour V, Borrell C, Bosch F, Fernández E, Macdonald $\mathrm{H}$, et al. Esteve Foundation Discussion Group. Conflict of interest in science communication: more than a financial issue. Report from Esteve Foundation Discussion Group, April 2009. Croat Med J. 2010;51:7-15.

16. Kušec V, Gelo M. Uniform ICMJE conflict of interest declaration form: report of test use in Croatian Medical Journal in 2009-2010. Croat Med J. 2010;51:285-6.

17. De Angelis CD, Drazen JM, Frizelle FA, Haug C, Hoey J, Horton R, et al. Is this clinical trial fully registered? A statement from the International Committee of Medical Journal Editors. Croat Med J. 2005;46:499- 501.

18. Laine C, Horton R, DeAngelis CD, Drazen JM, Frizelle FA, Godlee F, et al. Clinical trial registration: looking back and moving ahead. Croat Med J. 2007;48:289-91.

19. Marušić A, Huić M. Registration of clinical trials still moving ahead - September 2008 update to Uniform Requirements for Manuscripts Submitted to Biomedical Journals. Croat Med J. 2008;49:582-5.

20. Krleza-Jeric K, Lemmens T. 7th Revision of the Declaration of Helsinki: Good News for the Transparency of Clinical Trials. Croat Med J. 2009;50:105-10.

21. Marušić M, Sambunjak D, Marušić A. Life of small medical journal - how bibliographical indexing and international visibility affected editorial work in Croatian Medical Journal. Croat Med J. 2006;47:372-5. 